\title{
Caracterización das migracións no rural galego do século XXI
}

\author{
Migrations in the rural Galicia at the first XXI century \\ ROCÍO TOXO-ASOREI \\ Grupo de Investigación Ecoagrasoc (Gl-1899) \\ Escola Politécnica Superior de Enxeñaría \\ Universidade de Santiago de Compostela \\ ORCID: 0000-0001-5253-0829 \\ rociotoxo@gmail.com \\ ANA ISABEL GARCÍA-ARIAS \\ Grupo de Investigación Ecoagrasoc (Gl-1899) \\ Dpto. Economía Aplicada \\ Escola Politécnica Superior de Enxeñaría \\ Universidade de Santiago de Compostela \\ ORCID: 0000-0002-7440-0715 \\ anaisabel.garcia@usc.es
}

\section{RESUMO}

A literatura recente sobre migracións rurais en Europa centra o seu interese en coñecer as motivacións da poboación nova para emigrar e as consecuencias que iso ten para o desenvolvemento económico das rexións. Sen embargo, en Galicia existe unha importante carencia de investigacións centradas no éxodo da poboación do rural galego no século XXI, un feito que contrasta cos numerosos estudos realizados sobre a emigración histórica a América e a Europa. Tomando como referencia a clasificación dos concellos galegos segundo o grao e o subgrao de urbanización, realizouse unha caracterización dos movementos migratorios da poboación menor de 35 anos con orixe nas zonas pouco poboadas de Galicia. Desta maneira, preténdese que este artigo contribúa ao coñecemento dos factores que están detrás da forte perda de poboación nas zonas rurais no presente século, aspectos que resultan cruciais para poder afrontar os desafíos formulados polo problema demográfico.

Palabras chave: migración, éxodo rural, poboación xove, Galicia, século XXI.

\section{Abstract}

The recent literature on rural migrations in Europe focuses on knowing the reasons of young population for emigrating and their consequences in the economic development of the regions. However, in Galicia there is a significant lack of research focused on the exodus of the Galician rural population in the 21 st century, a fact that contrasts with the many studies on the historical migration 
to America and Europe. Taking as a reference the classification of the Galician municipalities according to their grade and subgrade of urbanization, a characterization of migratory movements of the population under 35 years old with origin in the sparsely populated areas was carried out. Thus, this paper aims to contribute to the knowledge of the factors behind the great population loss in the rural areas, which is crucial to deal with the challenges of the demographic problem.

Keywords: migration, rural exodus, young population, Galicia, 21st century.

\section{INTRODUCIÓN}

A análise da literatura científica relativa ás migracións en Galicia constata o enorme interese académico suscitado pola emigración histórica a América e a Europa entre os séculos XVI e XX [véxase Aldrey Vázquez (2003), Cagiao Vila et al. (2013), Eiras Roel (1992), Ferrás Sexto (2000), Hernández Borge (2003), Núñez Seixas (2001), Seijas Montero (2011), Villares Paz (1996)]. Este feito, contrasta coa carencia de investigacións centradas no estudo do éxodo da poboación rural no século XXI, estudos que resultan cruciais para poder afrontar os desafíos formulados polo «problema demográfico» en Galicia.

A pesares de que en Galicia o inicio do milenio produciuse de forma parella a un incremento da poboación total, que se mantería en auxe durante a primeira década do presente século, o ano 2010 supuxo o comezo dun novo período de decrecemento demográfico (Aldrey Vázquez e Del Río Franqueira, 2014). Este descenso poboacional estivo motivado pola confluencia dun aumento do saldo natural negativo e un saldo migratorio descendente, que pasou a ser negativo a partir do ano 2013 pero que recuperou no 2016 o seu signo positivo, ao descender o número de emigrantes con respecto aos anos anteriores. De acordo coas análises a escala provincial e comarcal, sabemos que a perda de habitantes produciuse de forma máis acentuada nas provincias interiores, especialmente naquelas áreas que presentan unha orografía máis pronunciada e/ou que se atopan situadas a unha maior distancia das principais cidades. Sen embargo, aínda que determinados municipios das provincias de Lugo e Ourense levan perdendo habitantes de forma ininterrompida incluso dende o año $1910^{1}$, en xeral pode afirmarse que este proceso de forte deterioro demográfico das áreas rurais galegas ten a súa orixe nos intensos procesos migratorios experimentados a partir dos anos sesenta [véxase Aldrey Vázquez (2006), Aldrey Vázquez e Lois González (2010), Lois González e Rodríguez González (2001), Lois González e Piñeira Mantiñán (2011), Martínez Filgueira et al., 2017]. Recentes traballos cartografían este proceso de despoboación a nivel parroquial e poñen de manifesto, aínda máis, o forte desequilibrio territorial que arrastra (Pazó e Moragón, 2018).

Por outra parte, a reestruturación rural de finais do século XX caracterizouse para o conxunto de España por un proceso de forte masculinización e polo envellecemento da

1 Información dispoñible na base de datos Alteraciones de los municipios en los Censos de Población desde 1842, no portal web do Instituto Nacional de Estadística (INE). 
poboación, fenómenos que teñen a súa orixe tamén na citada emigración dos anos 60 e 70 e no proceso de desagrarización (García Sanz, 2012). Ademais, investigacións recentes (Camarero e Sampedro, 2008) caracterizan a emigración rural protagonizada por mulleres en función do tipo de mercado laboral ao que ten acceso este grupo da poboación e que pode, ou non, favorecer a mobilidade ou a emigración.

Este traballo trata de determinar os principais trazos dos movementos migratorios nas zonas rurais galegas en función das variables sexo e idade, durante o período 2000 2015. Desta maneira, preténdese contribuír ao coñecemento dos factores que están detrás da forte perda de poboación nesta comunidade autónoma a inicios do século XXI.

\section{OS FENÓMENOS MIGRATORIOS NO ÚLTIMO DECENIO EN ESPAÑA E EUROPA: A CRISE NO RURAL E O FENÓMENO DO DESPOBOAMENTO}

$\mathrm{Na}$ actualidade, os procesos migratorios seguen a ser un fenómeno de interese política e socioeconómica en Europa, toda vez que novos paradigmas migratorios se teñen desenvolto (King, 2002). Aínda que o foco mediático céntrase na inmigración externa, non é menos importante o feito de que certos territorios no interior da Unión se desertizan. A sangría poboacional do rural continúa inexorable na Europa do século XXI, a pesares das políticas de cohesión rexional e de desenvolvemento rural que tiñan por obxectivo fixar poboación nestes territorios.

En canto á distribución da poboación no territorio, cabe sinalar que a poboación europea estase a concentrar no Centro-Oeste do continente (BBSR, 2016), sendo notorias as disparidades espaciais. Neste contexto, en moitos casos o crecemento das cidades faise a expensas das zonas rurais. Nos países nórdicos e na Europa do leste a tendencia da poboación é a concentrarse nas pequenas e medianas cidades das zonas rurais (BBSR, 2016). Pola contra, e tomando os países da UE-15, as zonas en declive poboacional son as predominantemente rurais, onde se concentra a menor parte da poboación $(14,8 \%$ en 2006, fronte ao 36,5\% dos países do Leste). Non obstante, as diferenzas por países, mesmo dentro do grupo dos 15, é ampla. Así, en Austria, Irlanda, Suecia ou Finlandia a proporción de poboación vivindo en áreas rurais sitúase entre o $45 \%$ e o 72 \% fronte ao 1-4 \% dos Países Baixos ou Gran Bretaña (Gáková e Dijkstra, 2010).

Por outra banda, dentro das áreas rurais europeas tamén existen diferenzas a destacar. Entre 1999 e 2004 as áreas rurais (NUTS 3) de Bélxica, Holanda, gran parte de Francia, Hungría e Irlanda experimentaron un crecemento prolongado na súa poboación, mentres que Lithuania e gran parte de Polonia experimentaron as maiores perdas de poboación nas zonas rurais (Poláková et al., 2011).

O fenómeno do éxodo rural foi ben estudado no pasado en relación aos procesos de desenvolvemento do sector industrial primeiro e do sector servizos despois, así como da expansión das cidades. As zonas rurais subministraron materias primas e man de 
obra para a industria durante séculos, acompañando un proceso de urbanización cada vez maior e de perda de peso da agricultura, en termos de emprego e valor da produción (Fielding 1989; Pinilla, Ayuda e Sáez, 2008). Así, o despoboamento rural ten sido cualificado como endémico en Europa (Stockdale, 2006) dada a súa continuidade dende a metade do XIX e debe ser entendido como o proceso polo cal, en certas zonas, o éxodo rural sobrepasa o crecemento natural, reducindo o número total de habitantes ata un nivel crítico polas baixas densidades poboacionais (Pinilla, Ayuda e Sáez, 2008). En consecuencia, a estrutura demográfica resultante está caracterizada por altos niveis de masculinización e avellentamento (Camarero e Sampedro, 2008).O despoboamento rural ten sido cualificado como endémico en Europa (Stockdale, 2006) dada a súa continuidade dende a metade do XIX e debe ser entendido como o proceso polo cal, en certas zonas, o éxodo rural sobrepasa o crecemento natural, reducindo o número total de habitantes ata un nivel crítico polas baixas densidades poboacionais (Pinilla, Ayuda e Sáez, 2008). En consecuencia, a estrutura demográfica resultante está caracterizada por altos niveis de masculinización e avellentamento (Camarero e Sampedro, 2008).

A literatura sobre migracións rurais centrou o seu interese en coñecer as motivacións da poboación nova para emigrar e nas consecuencias que isto ten para o desenvolvemento económico destas rexións. Tamén preocupa a escasa capacidade para que as zonas rurais —especialmente as máis remotas - atraian inmigrantes extracomunitarios, xa que estes se concentran maioritariamente nas cidades. Recentemente os efectos da crise sobre os movementos migratorios son obxecto de atención.

Stockdale $(2002,2004,2006)$ analiza os fenómenos da despoboación e das migracións rurais en Escocia distinguindo entre inmigración, emigración e o fenómeno do retorno dos emigrantes. A autora sostén que o fenómeno do despoboamento ten fundamentalmente que ver coa emigración da xente nova e destaca como motivación para marchar o acceso a un certo nivel educativo e profesional. Rérat (2014) e Fielding (1989) recollen esta motivación para Francia e o sur de Inglaterra respectivamente.

O éxodo en resposta á falta de oportunidades laborais é citado como o segundo motivo nos traballos de Stockdale (2006) e Thissen et al. (2010) sinálao como primeiro nas zonas rurais flamencas. A falta de oportunidades laborais e o desexo de mellora nas condicións de vida e no estatus social ("fuxida ilustrada") foi unha das principais motivacións presentes nos estudos sobre a emigración rural feminina (Camarero e Sampedro, 2008; Whatmore, 1991; Almås e Haugen, 1991) e supérase unha vez rematado o proceso de desagrarización e acabado o modelo fordista de emprego que "maximizaba a eficacia dos estudos como instrumento de ascenso social", nun momento no que as cualificacións formativas das mulleres rurais son superiores en moitas ocasións á media masculina. Mendola (2012) subliña a feminización dos movementos migratorios en diversas partes do mundo e demostra a necesidade da realización dos estudos de xénero na abordaxe das migracións.

Merece tamén especial atención o papel da desagrarización e da reestruturación rural (Marsden, Lowe and Whatmore, 1990) na expulsión de poboación das zonas rurais. A desagrarización é unha das consecuencias do chamado produtivismo que ten como tra- 
zos característicos en agricultura a intensificación, a concentración e a especialización da produción. Estes fenómenos deixan de intensificarse no norte europeo nos anos 80, pero seguen a incrementarse no sur durante os 80 e 90 como o caso da Cornixa Cantábrica en España (Sineiro García et al., 2006; Arnalte-Alegre e Ortiz-Miranda, 2013). A concentración da produción nuns territorios que se especializan, leva ao abandono doutras zonas, coa conseguinte desaparición de explotacións e éxodo da poboación se o territorio rural non é quen de xerar oportunidades de emprego alternativas á agricultura.

Non obstante, na Europa do posprodutivismo agrario, os neorrurais e o fenómeno da contraurbanización teñen xogado un papel importante no crecemento das vilas de tamaño intermedio no centro e oeste do continente, ata os anos 80 (Fielding, 1989). Este movemento das familias de clase media para instalarse nas conurbacións das grandes urbes e desprazarse a traballar ten mudado o concepto de mercado de traballo para os habitantes do rural (Camarero e Sampedro, 2008) e ten provocado dificultades na convivencia cos habitantes orixinarios destas zonas, mais tamén ten revitalizado economicamente esas áreas.

En canto á instalación de inmigrantes estranxeiros, cando se trata de zonas rurais remotas, Stockdale (2006) non atopa unha evidencia significativa da capacidade do movementos inmigratorios para soster un desenvolvemento endóxeno. Outra é a evidencia no sur de Europa, España e Portugal fundamentalmente, onde o fenómeno da inmigración nas zonas rurais está ligado na última década do século XX a unha intensificación dos procesos produtivistas na agricultura. As explotacións intensivas realizaron a súa expansión grazas á man de obra inmigrante, nun contexto de alta demanda de produtos hortícolas no norte de Europa e falta de efectivos agrarios no sur, xa que foran expulsados nos procesos de reestruturación anteriores. Este tipo de inmigrantes non posúen cualificación profesional, pero permitiron unha certa renovación demográfica nos primeiros anos do século XXI ata a chegada da crise (Arnalte-Alegre e Ortiz-Miranda, 2013) cando se inicia un ciclo de atenuación dos fluxos de entrada de inmigrantes estranxeiros e unha activación dos fluxos de saída tanto de nacionais como de estranxeiros (Gil-Alonso et al, 2015; Domingo i Valls et al., 2014).

Outro dos movementos migratorios rexistrados en certas zonas rurais europeas -especialmente do sur do continente- é o dos inmigrantes retornados unha vez alcanzada a idade de xubilación. Este grupo de persoas non supón unha dotación de capital para o desenvolvemento, pero si constrúe unha nova demanda nas áreas rurais para todo tipo de servizos (Stockdale, 2006), especialmente aqueles relacionados coa economía dos coidados. Non obstante, a crise ten dado unha nova forma ao movemento de retorno de inmigrantes no conxunto de Europa, xa que supón en moitas áreas a reversión dos fluxos migratorios. Os efectos da crise no caso español teñen sido recentemente estudados (Domingo i Valls et al., 2014; Gil-Alonso et al., 2015; López de Lera e Pérez-Caramés, 2015) e merece a nosa atención neste apartado en canto ás diversas consecuencias migratorias para as áreas rurais.

A crise, especialmente a partires de 2011 , ten mudado tanto a densidade dos fluxos migratorios internos, que diminúen, como o seu patrón espacial (Gil-Alonso et al., 2015). 
Se ben antes da crise as zonas rurais do sur recibían inmigración estranxeira e eran, á súa vez, punto de distribución desta emigración cara a áreas máis poboadas e urbanizadas, despois da crise as migracións cara as outras zonas internas redúcense pero fréase tamén a chegada de inmigrantes. Deste xeito, detéctase como o sector agrario aparece nestas áreas como un sector refuxio para aquela poboación migrante que xa non atopa traballo na construción como antano. Gil-Alonso et al. (2015) detectan como certas áreas rurais, a Cornixa Cantábrica por exemplo, son agora destino dos migrantes estranxeiros e rexistran fluxos migratorios internos positivos así como unha certa fixación residencial da poboación estranxeira que non retorna. Neste senso, parece que nos primeiros anos da crise foi a poboación estranxeira a que engrosou os fluxos da emigración cara fóra de España (Domingo i Valls et al., 2014), mentres que a partires das políticas de axuste que se sucederon despois de 2010, son os nacidos en España os que se deciden a emigrar.

As consecuencias para as zonas rurais do éxodo da xente nova teñen sido estudadas dende diversos puntos de vista. Deste xeito, apuntáronse consecuencias ambientais e paisaxísticas, consecuencias demográficas como o avellentamento e a masculinización, a perda de capital humano, a perda de servizos... Todas elas, retroalimentan o éxodo e impiden a rexeneración, en termos de desenvolvemento. Pola contra, as áreas rurais que experimentan un rápido crecemento demográfico (debido á contraurbanización, ao desenvolvemento dos desprazamentos para ir traballar ás urbes, aos retornados ou á inmigración para traballar nas explotacións intensivas), ven medrar unha maior presión sobre os recursos, tanto ambientais como infraestruturas ou servizos, con tensións non sempre fáciles de resolver pero posibilitando unha maior diversificación económica neses territorios (Pólaková et al., 2011).

\section{METODOLOXÍA}

Para a delimitación dos municipios rurais de Galicia elixiuse a Clasificación do grao e subgrao de urbanización dos concellos (GU-2016), elaborada polo Instituto Galego de Estatística (IGE, 2016)². De acordo con Bielza (2010), no contexto do mundo industrializado, as áreas de baixa densidade urbana correspóndense coas zonas de menor densidade de poboación, razón pola que neste traballo se consideraron as ZPP coma as áreas rurais (figura 1). Para a descrición de cada unha destas zonas, recorreuse aos datos dos indicadores demográficos, sociolaborais e económicos do Panorama rural-urbano publicados no sitio web do IGE. No caso do índice de masculinidade, ao non estar os datos dispoñibles para as diferentes categorías da clasificación, calculouse a partir do cociente entre o número total de homes e o número total de mulleres de cada zona, multiplicado por cen.

2 A documentación relativa a esta clasificación está dispoñible no portal web do IGE. https://www.ige.eu/web/mostrar_paxina.jsp?paxina=003003001\&idioma=gl 


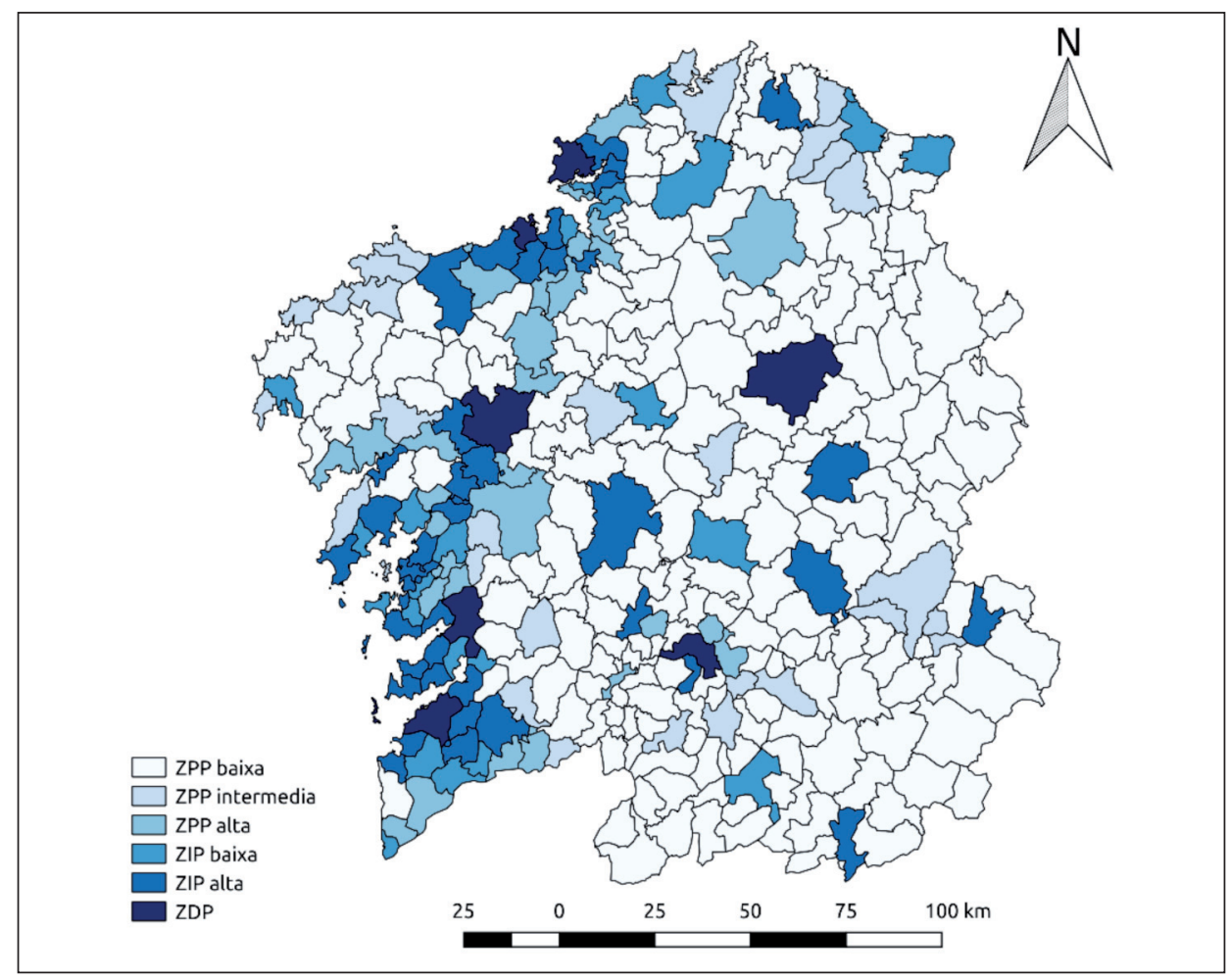

Figura 1. Mapa dos concellos de Galicia segundo o subgrao de urbanización (GU 2016).

Fonte: elaboración propia a partir da Clasificación do grao e subgrao de urbanización dos concellos (GU-2016) (IGE).

Dados os obxectivos formulados, seleccionáronse os 241 municipios da ZPP (ZPP alta, ZPP intermedia e ZPP baixa) para caracterizar a súa evolución demográfica e migratoria no período 2000-2015. Tras realizar unha valoración da calidade e adecuación das diferentes fontes estatísticas de datos sobre migracións, optouse por tomar como base os datos das migracións ofrecidos polo IGE, elaborados a partir da Estatística de Variacións Residenciais (INE). Os datos desta fonte proveñen da explotación das altas e baixas no Padrón municipal de habitantes, polo que se ven afectados polas limitacións derivadas do Padrón. Neste sentido, na Estatística de Variacións Residenciais (EVR) non se miden as migracións, senón que se miden as comunicacións de cambios de domicilio que implican unha modificación no municipio de residencia e que se derivan, ou non, dunha migración. Polo tanto, non todas as migracións son incorporadas no Padrón e incluso poder haber rexistros que non se corresponden con feitos reais, á parte de que unha mesma persoa pode comunicar varios cambios de domicilio nun período curto de tempo. Deste xeito, existen certas distorsións na interpretación dos datos que non poden ser obviadas, xa que empadronarse ás veces responde máis a unha necesidade probatoria fronte á administración (por exemplo no contexto da escolarización dos nenos e nenas) que a un cambio de 
domicilio real. Isto afecta de xeito especial á interpretación das migracións interprovinciais. Con todo, e a pesares das discrepancias que existen entre as diversas fontes de datos sobre migracións, a Estatística de Variacións Residenciais segue sendo a principal fonte de datos a este respecto e a única que realmente mide migracións (Susino Arbucias, 2011; García Coll e Sánchez Aguilera, 2001). Polo tanto, foi a partir dos datos da EVR que se analizaron os saldos migratorios e o impacto de cada tipo de migración en función das variables sexo e idade. Este último estudo, realizouse mediante o cálculo e a comparación das taxas brutas de emigración nos diferentes grupos de idade.

Polo que se refire á análise dos saldos migratorios para cada unha das seis zonas da clasificación GU-2016 e para o período 2000-2015, calculouse o sumatorio dos saldos migratorios anuais de cada un dos concellos correspondentes a cada zona, a partir dos datos descargados da web do IGE. Pola súa parte, a taxa bruta de emigración definiuse coma o cociente entre o total de emigracións e a poboación media no ano de referencia, por cada 1.000 habitantes. Debido a que os datos de poboación foron tomados do Padrón municipal de habitantes e esta fonte non nos permite coñecer a poboación a 1 de xullo, a poboación media foi calculada coma a metade da suma da poboación habida no ano de referencia e no seguinte. Finalmente, dada a escasa relevancia das migracións na poboación menor de 15 anos e na poboación maior de 65 anos en termos estatísticos, estableceuse un grupo de idade de 0-15 anos e outro grupo de 65 e máis anos. Ao primeiro destes grupos de idade séguelle o de 16-19 anos e, todos os sucesivos ata chegar ao de 65 e máis anos, son grupos de idade quinquenais. Sen embargo, a imposibilidade de obter datos de emigracións para todos os grupos de idade dende o inicio do período de estudo fixo que a análise das emigracións segundo sexo e idade se centrase no período 2005-2015.

\section{A CLASIFICACIÓN DOS CONCELLOS GALEGOS SEGUNDO O GRAO E O SUBGRAO DE URBANIZACIÓN}

A Clasificación do grao e subgrao de urbanización dos concellos galegos (GU2016), elaborada polo Instituto Galego de Estatística (IGE, 2016), está baseada na metodoloxía da Clasificación do Grao de Urbanización elaborada no ano 2011 por Eurostat e outros organismos da Unión Europea e a Organización para a Cooperación e o Desenvolvemento Económico. Esta clasificación, divide os municipios galegos en tres zonas principais atendendo ao grao de urbanización: Zonas Densamente Poboadas (ZDP), Zonas Intermedias (ZIP) e Zonas Pouco Poboadas (ZPP). Á súa vez, as categorías ZIP e ZPP subdivídense en dúas e tres subcategorías, respectivamente, en función do subgrao de urbanización. Desta maneira, tal e como se puido observar na figura 1, obtense unha clasificación dos municipios galegos nun total de seis zonas: ZDP, ZIP alta, ZIP baixa, ZPP alta, ZPP intermedia e ZPP baixa.

A heteroxeneidade do territorio galego reflíctese nas dinámicas demográficas das diferentes zonas, atopándose xeralmente os maiores contrastes entre a ZIP alta e a ZPP 
baixa. As zonas pouco poboadas, intermedia e baixa, foron as únicas que rexistraron descensos no número de habitantes no período 2002-2015, presentando importantes perdas de efectivos demográficos (11,7 \% a ZPP intermedia e 18,2 \% a ZPP baixa). Non obstante, o crecemento demográfico relativo nas restantes zonas non foi moi significativo, coa excepción da ZIP alta, que incrementou no 2015 a súa poboación en máis dun $11 \%$ con respecto ao ano 2002. Tendo en conta que o crecemento poboacional a nivel de Galicia foi negativo para todo o período, os datos dos incrementos demográficos rexistrados na ZDP, na ZIP alta, na ZIP baixa e na ZPP alta amosan a dirección dos movementos migratorios internos dos galegos e galegas con orixe nas ZPP intermedia e baixa, así coma o destino das emigracións con orixe fóra de Galicia. En consecuencia, a idade media destas zonas rurais é tamén a que máis se incrementou durante o período de estudio, pasando na ZPP intermedia de 45,5 anos no 2002 a 49,6 no 2015 e na ZPP baixa de 49 a 53,2 respectivamente. Curiosamente, foi na ZPP alta na categoría que menos se incrementou a idade media da poboación durante o período 2002-2015, aumentando a un ritmo menor que nas zonas que presentaron os maiores valores no índice sintético de fecundidade e os menores valores do índice de envellecemento (ZDP, ZIP alta e ZIP baixa). Con respecto a este último indicador, cabe destacar o significativo aumento que experimentou na ZPP intermedia e na baixa, pasando no primeiro caso de 159,3 no ano 2002 ao 232,5 no ano 2015 e, no segundo caso, de 237,6 a 365,1 respectivamente. Isto tradúcese en que no ano 2015 na ZPP intermedia había 232 persoas de 65 ou máis anos por cada cen persoas menores de vinte anos e, na ZPP baixa, 365 por cada cen menores de vinte anos.

Estas diferencias nas pautas do comportamento demográfico das diferentes categorías da clasificación, están estreitamente vencelladas ás súas dinámicas económicas. Pois as zonas máis dinámicas a nivel demográfico (ZIP alta e ZIP baixa) correspóndense na inmensa maioría con municipios litorais considerados urbanos (Vázquez, Sineiro e Lorenzana, 2008), tendo en conta que os municipios de A Coruña, Ferrol, Santiago de Compostela, Lugo, Ourense, Pontevedra e Vigo están dentro da ZDP. Desta maneira, as zonas rurais de Galicia asimilaríanse cos douscentos corenta e un municipios que conforman a ZPP alta, a ZPP intermedia e a ZPP baixa, municipios que se caracterizan por ter en común o ser emisores de efectivos demográficos ás restantes zonas de Galicia —ao igual que acontece en amplas zonas da periferia europea- e por estar situados en zonas do interior e lonxe das principais cidades, en áreas montañosas de difícil acceso ou por ser concellos da zona atlántica situados fóra do Eixo Atlántico. Esa gradación que introduce o subgrao de urbanización co establecemento das seis categorías, reflíctese perfectamente nas porcentaxes de afiliacións á Seguridade Social nos sectores primario e terciario, que aumentan e diminúen de forma directamente proporcional en base ao maior ou menor grao de urbanización do territorio na maior parte dos casos. Mais, sen dúbida, onde maior se apreciou unha relación directa entre economía e grao de urbanización foi no rendemento medio declarado no IRPF, aumentando a medida que se incrementa o nivel de urbanización e viceversa (táboa 1). 


\section{OS MOVEMENTOS MIGRATORIOS NAS ZONAS POUCO POBOADAS}

A ZPP abarca o 81,8 \% (IGE, 2016) da superficie de Galicia e concentra o 76,6\% do total dos municipios ${ }^{3}$. No ano 2015 o volume de poboación que vivía nestas zonas representaba o $31 \%$ da poboación total de Galicia, un 3,3\% menos que no ano 2000. A diferenza da evolución demográfica seguida en Galicia durante o período 2000-2015, a ZPP iniciou o século XXI partindo dun escenario de decrecemento continuado - carrexado dende mediados do século anterior - que se agravou especialmente a partir do ano 2008 e que se acentuou, aínda máis, a partir do ano 2011. Isto traduciuse nunha variación poboacional negativa do $13,8 \%$ no ano 2015, con respecto ao ano 2000. Sen embargo, ao analizar a variación da poboación en función do subgrao de urbanización, observouse que a perda de efectivos demográficos nas diferentes subcategorías da ZPP é maior canto menor é o grao de urbanización de cada zona. Desta forma, nos dezaseis anos que toma o período de estudo, a ZPP baixa perdeu o 20,4 \% da poboación, a ZPP intermedia o $13,2 \%$ e a ZPP alta o $3,11 \%$.

A análise do saldo migratorio que presentaron as diferentes zonas rurais de Galicia no período de estudo, mostrou que a ZPP intermedia e a ZPP baixa foron as únicas zonas de Galicia que presentaron un saldo migratorio negativo (na ZPP intermedia de 1.413 persoas e na ZPP baixa de 13.634 persoas), ilustrando un fenómeno de baleirado en favor da concentración da poboación rural nas cabeceiras de comarca (ZPP alta), onde se atopan a maior parte dos servizos. Así, a ZPP alta tivo un saldo migratorio positivo de 19.774 persoas, se ben as características da emigración nesta zona foron moi similares ás detectadas na ZPP intermedia e na ZPP baixa.

Se descendemos na análise ao nivel provincial (gráfica 2), obsérvase que as provincias do litoral foron as que mostraron os valores máis elevados do saldo migratorio na ZPP alta (10.397 persoas en A Coruña, 6.262 en Pontevedra, 440 en Lugo e 2.675 en Ourense). No caso da provincia de A Coruña, a pesares de presentar o saldo migratorio positivo máis elevado para esa zona, amosou tamén o maior saldo migratorio negativo das catro provincias tanto na ZPP intermedia (2.927 persoas) coma na ZPP baixa (5.546 persoas). Pola contra, se ben a provincia de Pontevedra tivo unha cifra menor no saldo migratorio da ZPP alta con respecto á de A Coruña, na ZPP intermedia o valor do saldo migratorio foi negativo — aínda que non moi significativo (79 persoas) — e foi a única provincia que presentou cifras positivas no saldo migratorio da ZPP baixa (22 persoas). En A Coruña e Pontevedra, o saldo migratorio positivo da ZPP alta pode explicarse tamén pola contraurbanización (Fielding, 1989), producida polo abandono da cidade por parte da poboación urbana, nomeadamente de A Coruña e Vigo, ou polo asentamento nas zonas rurais — máis baratas — da forza de traballo que alimenta a industria e a construción favorecido polas boas comunicacións no Eixo Atlantico.

3 No período de estudo, había en Galicia 314 municipios, tras a fusión de Oza-Cesures no ano 2013. 
En canto ás provincias do interior Lugo foi a que acadou as peores cifras, presentando un lixeiro saldo migratorio positivo na ZPP alta e un saldo migratorio negativo de 544 persoas na ZPP intermedia, un valor que se nonuplicou na ZPP baixa (-4.988 persoas). Sen embargo, a provincia de Ourense presentou valores positivos no saldo migratorio da ZPP alta e da ZPP intermedia (2.137 persoas) e un saldo migratorio negativo de 3.122 persoas na ZPP baixa, unha cifra notablemente inferior á do caso de Lugo e moito máis inferior á da provincia da Coruña. Ourense parece un caso atípico, pero só pode explicarse pola escasísima poboación que queda xa na ZPP baixa, concentrándose a maior parte no resto de zonas.

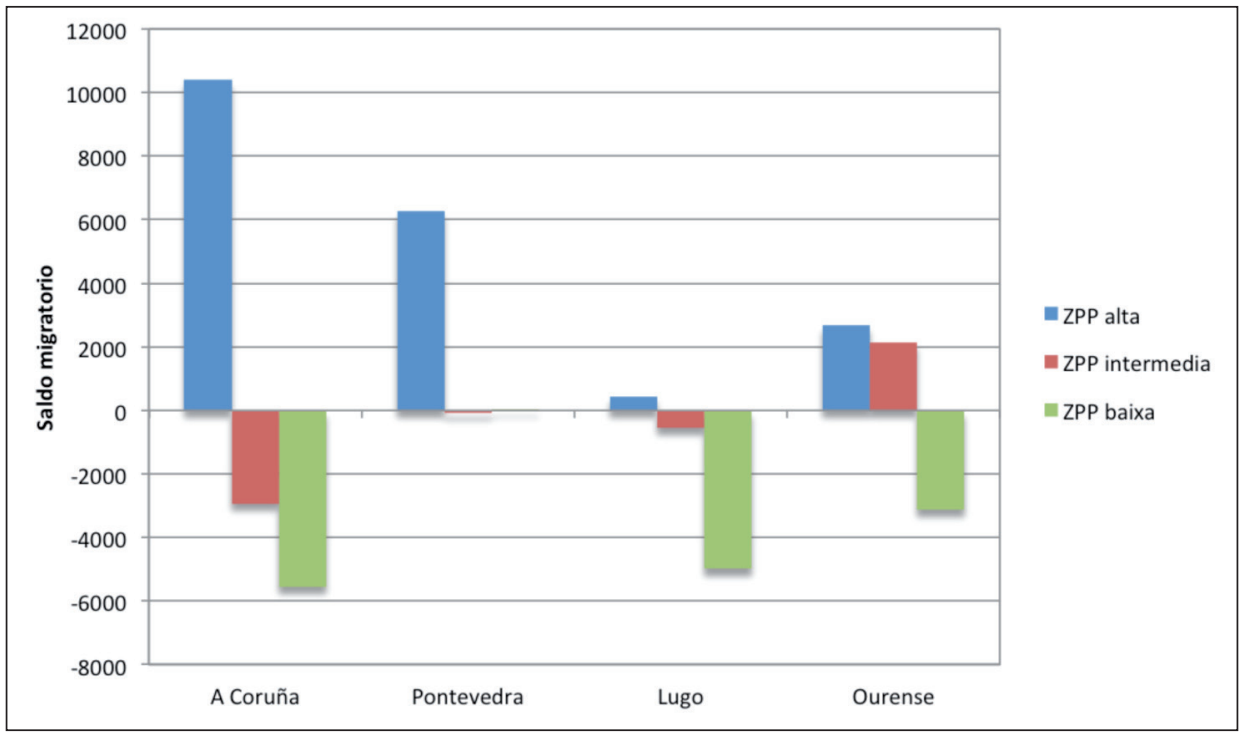

Figura 2. Saldo migratorio na ZPP alta, na ZPP intermedia e na ZPP baixa, segundo a provincia (2000-2015). Fonte: elaboración propia a partir dos datos dos saldos migratorios (IGE).

A figura 3 ilustra a evolución da taxa bruta de emigración que aumentou de forma continuada nas tres zonas pouco poboadas durante o período 2000-2015. Non obstante, o maior incremento das taxas tivo lugar entre os anos 2000 e 2005, anos previos ao comezo da crise onde o sector da construción atraía poboación activa cara ás zonas urbanas. $\mathrm{Na}$ ZPP alta a taxa bruta de emigración pasou do 20,07 \% no ano 2000 ao 26,82 \%o no ano 2005. Pola súa parte, a taxa bruta de emigración do $21,71 \%$ que se produciu na ZPP intermedia no ano 2000, chegou a ascender no 2005 ao 29,05\%o. De forma parella, a ZPP baixa partiu no ano 2000 cunha taxa bruta de emigración do $21,24 \%$ e incrementou a cifra no ano 2005 ata situarse no $27,74 \%$.

Sen embargo, unha vez que estala a crise vemos como entre os anos 2005 e 2010 a taxa bruta de emigración, aínda que continúa a súa tendencia, atenúa o seu ritmo de crecemento (a 
ZPP alta pasou dunha taxa do 26,82 \%o ao 30,08 \%o; a ZPP intermedia, pasou do 29,05 \%o ao $32,83 \%$; e a ZPP baixa pasou do $27,74 \%$ ao $33,47 \%$ ). Esta moderación no incremento dos valores da taxa amosou un certo estancamento entre os anos 2010 e 2015 coherentemente co paro na actividade económica, especialmente na ZPP intermedia (a ZPP alta presentou no ano 2015 unha taxa do 32,53\% \% na ZPP intermedia o valor da taxa foi do 33,99\%o; e na ZPP baixa a cifra no 2015 era do 34,85 \%o). Tomando o período de estudo enteiro, o valor máis elevado na variación da taxa bruta de emigración total rexistrouse na ZPP baixa $(13,60 \%$ ), seguida pola ZPP alta $(12,46 \%$ ) e a ZPP intermedia $(11,28 \%$ ).

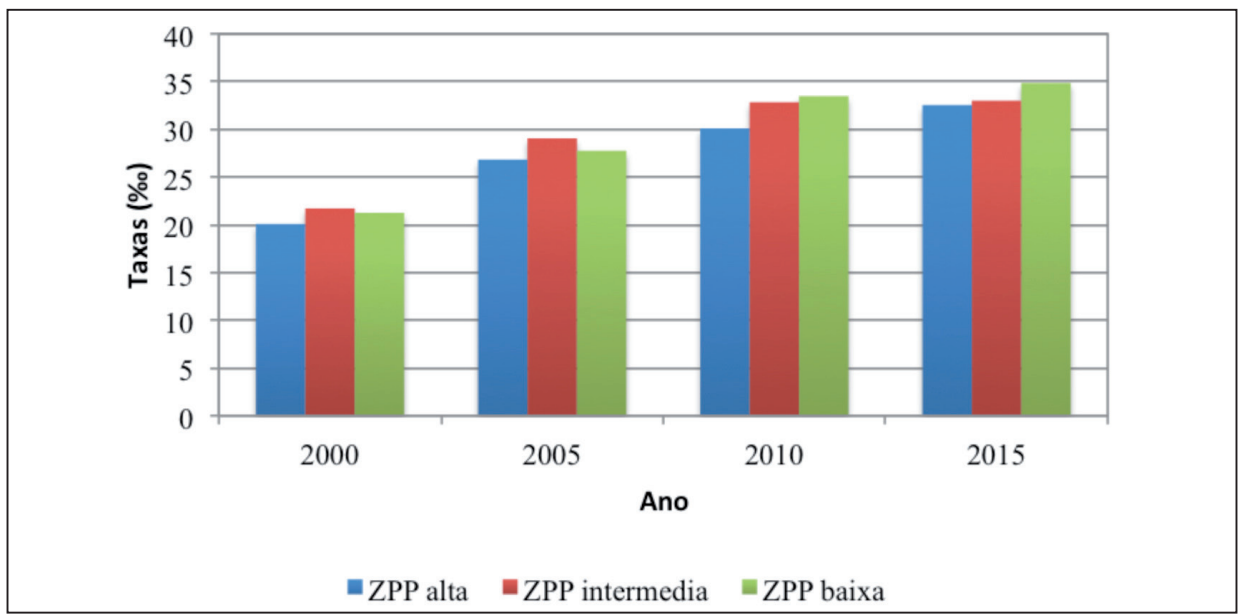

Figura 3. Evolución da taxa bruta de emigración total (\%o) na ZPP alta, na ZPP intermedia e na ZPP baixa (2000-2015).

Fonte: elaboración propia a partir dos datos de emigración segundo tipo de migración (IGE).

A devantida ralentización na tendencia crecente da taxa bruta de emigración total acaecida entre os anos 2010 e 2015, apréciase tamén neses mesmos anos nos valores da taxa bruta de emigración interna nas zonas pouco poboadas, mais non ocorre así na emigración externa. Neste último tipo de emigración, produciuse un certo estancamento dos valores da taxa entre os anos 2005 e 2010, mais no 2015 volvéronse a rexistrar novos incrementos moderados. Cómpre apuntar, como hipótese, que este lixeiro repunte responda ao retorno de persoas nacidas no estranxeiro aos seus lugares de orixe, e en menor medida, a nacidos en Galicia buscando mellores oportunidades fóra (Domingo i Valls et al., 2015).

En xeral, nas zonas pouco poboadas, os valores máis elevados nas taxas brutas de emigración interna durante o período 2000-2015 tiveron lugar na ZPP baixa, aínda que os maiores incrementos neses anos déronse na ZPP alta (no ano 2000 a ZPP alta presentaba unha taxa bruta de emigración interna do $14,79 \%$ e no ano 2015 pasou a ser do 24,53\%o, incrementándose neses dezaseis anos nun 9,73\%o). A diferenciación por períodos (figura 4), permite apreciar como a partires do ano 2005 o ritmo de incremento desta variable ralentízase, e 
estáncase practicamente entre 2010 e 2015 para as ZPP alta e media. Só a ZPP baixa continúa expulsando poboación cara a outras zonas do país. Esta evolución pode ser atribuída á crise e á falta de expectativas de atopar oportunidades económicas noutras zonas xeográficas.

As taxas brutas de emigración externa son inferiores ás de emigración interna e apenas experimentaron variación no seu ritmo ao longo do período estudado. Os valores máis altos víronse na ZPP intermedia, pero os incrementos máis elevados durante dito período tiveron lugar na ZPP baixa, que pasou de ter unha taxa bruta de emigración externa do 4,57 \%o no ano 2000 ao 8,57 \% no 2015 (figuras 4 e 5). De novo, a ZPP baixa é a que expulsa poboación.

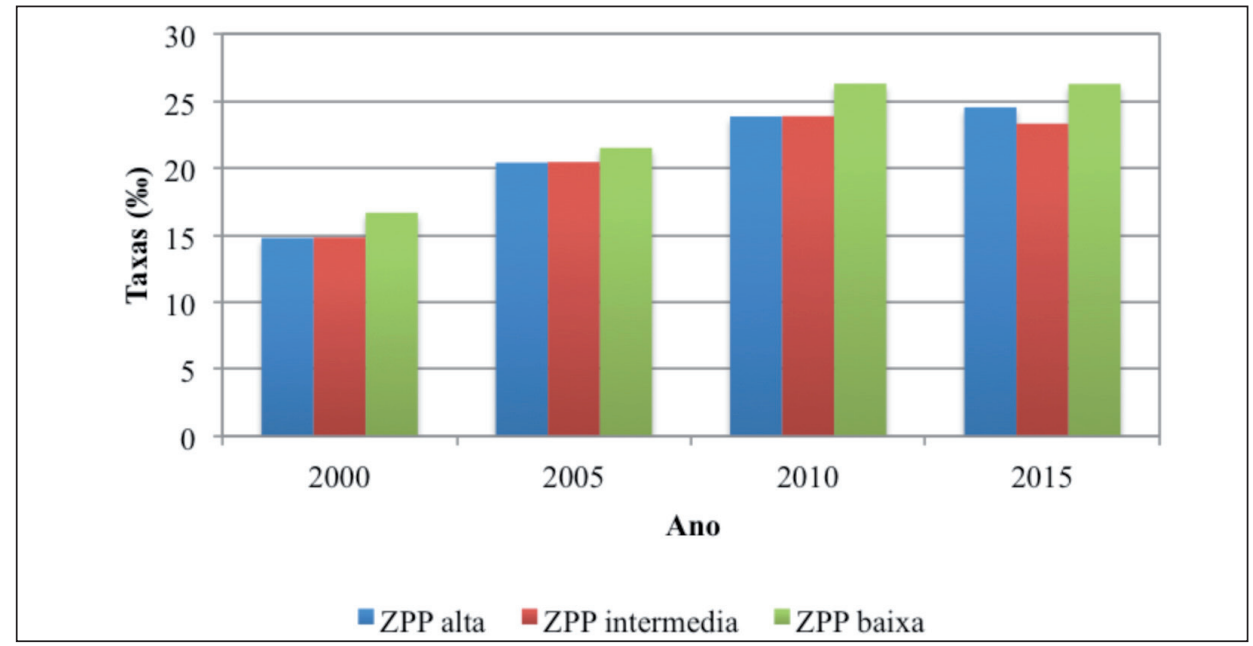

Figura 4. Evolución da taxa bruta de emigración interna na ZPP alta, na ZPP intermedia e na ZPP baixa, segundo o subgrao de urbanización (2000-2015).

Fonte: elaboración propia a partir dos datos de emigración segundo tipo de migración (IGE).

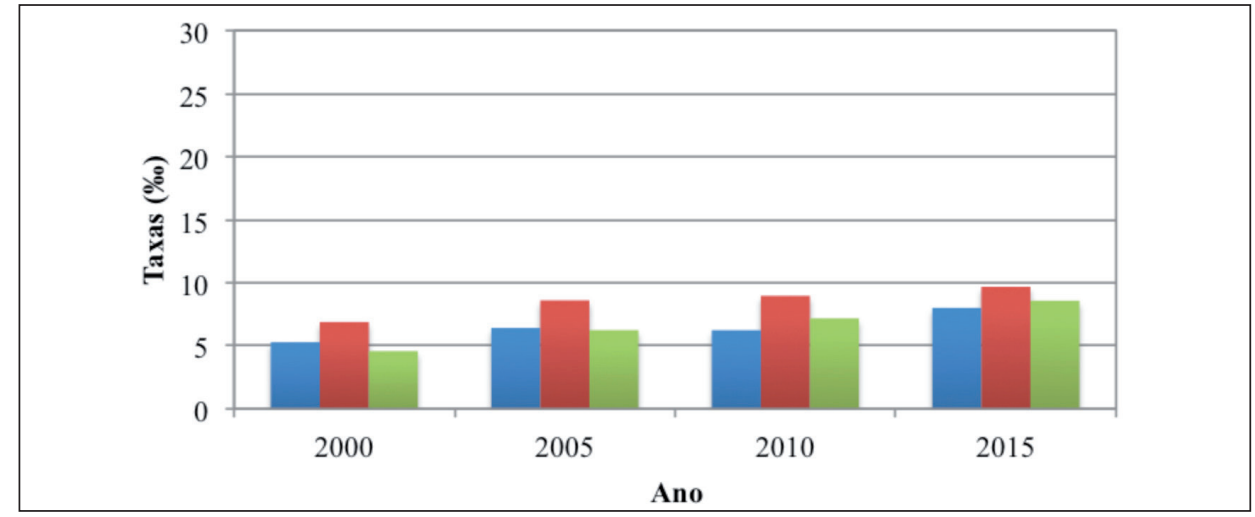

Figura 5. Evolución da taxa bruta de emigración externa na ZPP alta, na ZPP intermedia e na ZPP baixa segundo o subgrao de urbanización (2000-2015).

Fonte: elaboración propia a partir dos datos de emigración segundo tipo de migración (IGE). 
Tal e como se observa nas figuras 6, 7 e 8, os grupos de idade que rexistraron unha maior taxa bruta de emigración no período 2005-2015 nas tres zonas da ZPP, foron o de 25 a 29 anos e o de 30 a 34 anos. En xeral, o primeiro destes grupos etarios sinalado foi o máis afectado, coa excepción de que no ano 2015 na ZPP baixa o grupo de idade que mostrou a maior taxa bruta de emigración foi o de 30 a 34 anos, seguido polo de 25 a 29 anos. Non obstante, destaca o notable incremento producido nas taxas brutas de emigración no ano 2015, con respecto ao 2005, acusando o citado período de crise económica. Tamén é destacable a existencia de importantes disparidades nas taxas brutas de emigración entre sexos, diferenzas que se acentuaron enormemente no ano 2015 con respecto ao 2005. Nas tres zonas, no ano 2015, as maiores desigualdades atopáronse no grupo de idade de 25 a 29 anos, principalmente na ZPP alta (64\%o nos homes e $88 \%$ nas mulleres) e na ZPP baixa (69\% nos homes e $89 \%$ nas mulleres), e, en menor medida, na ZPP intermedia (69\%o nos homes e $87 \%$ nas mulleres).

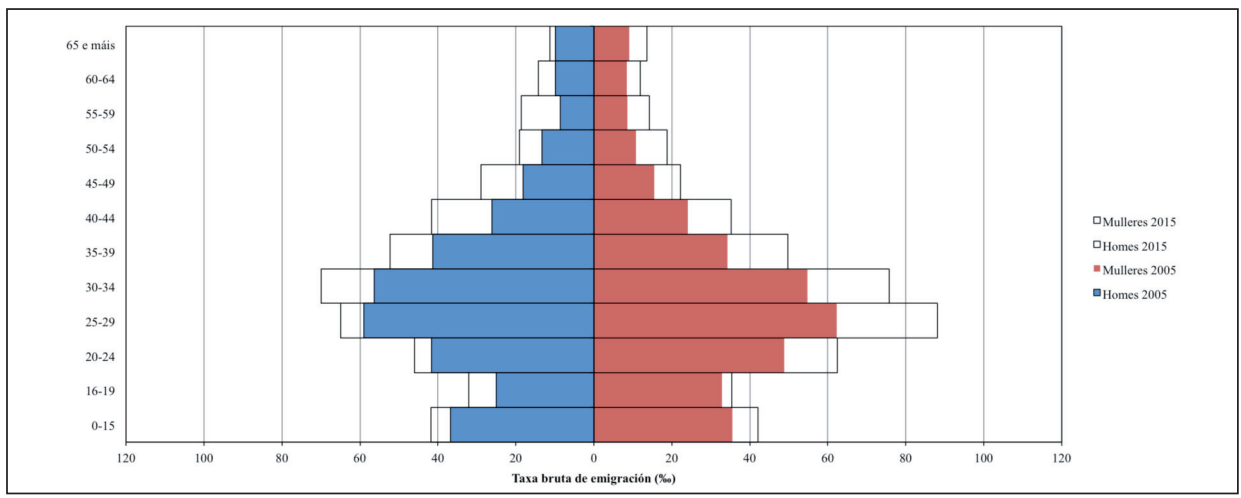

Figura 6. Taxa bruta de emigración segundo sexo e idade na ZPP alta (2005-2015).

Fonte: elaboración propia a partir dos datos de emigración segundo tipo de migración, sexo e idade proporcionados polo IGE.

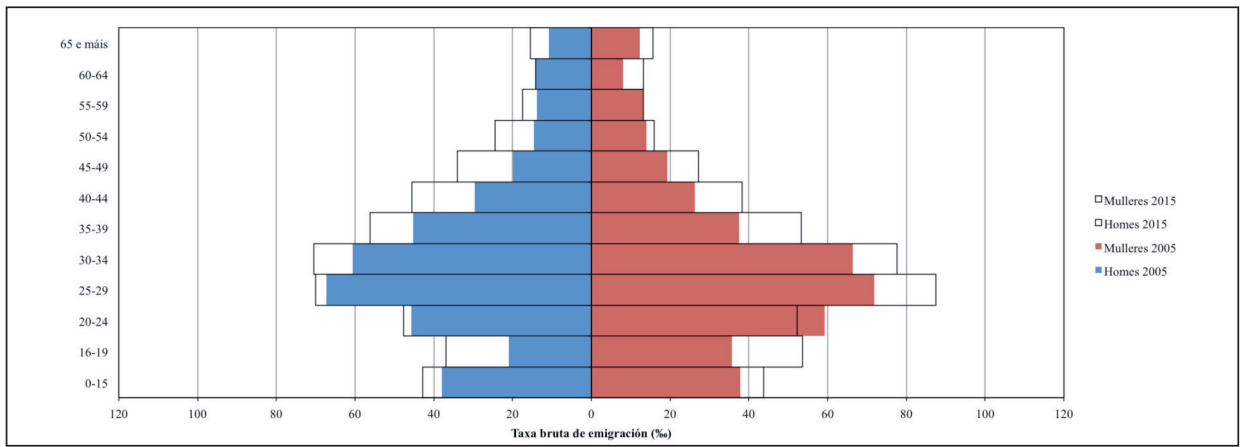

Figura 7. Taxa bruta de emigración segundo sexo e idade na ZPP intermedia (2005-2015).

Fonte: elaboración propia a partir dos datos de emigración segundo tipo de migración, sexo e idade proporcionados polo IGE. 


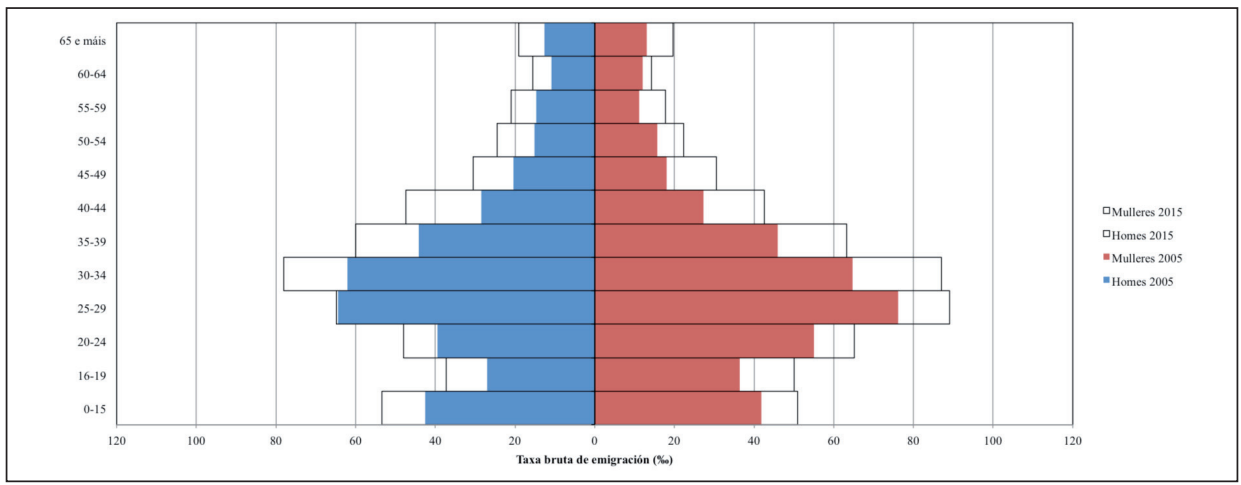

Figura 8. Taxa bruta de emigración segundo sexo e idade na ZPP baixa (2005-2015).

Fonte: elaboración propia a partir dos datos de emigración segundo tipo de migración, sexo e idade proporcionados polo IGE.

Os principais destinos das emigracións internas da poboación menor de 35 anos con orixe nas ZPP durante o período 2000-2015, foron a ZDP e a ZIP alta. Mais resulta chamativo o feito de que na ZPP alta o terceiro destino das emigracións da poboación neste rango de idades fose a ZIP baixa, mentres que nas ZPP intermedia e baixa foi a ZPP baixa.

\section{DISCUSIÓN E CONCLUSIÓNS}

A tenor dos resultados obtidos, evidénciase un fenómeno claro de concentración poboacional na ZDP e na ZIP, provocando unha constante e crecente perda de efectivos demográficos na ZPP, en coherencia coa literatura precedente (Pazó e Moragón, 2018). Neste senso, situámonos na situación descrita para os países nórdicos e os países do leste, onde a poboación das zonas rurais estase a concentrar nas cabeceiras de comarca, que agrupan os servizos e o resto de actividades económicas distintas da agro-gandeira.

A nosa análise afonda nas tres subcategorías da ZPP, observando unha relación directa entre o grao de urbanización do territorio e a súa capacidade para reter a súa propia poboación, sendo a ZPP baixa a zona máis afectada. Neste senso, nas provincias máis dinámicas, do Eixo Atlántico, as grandes urbes e a súa oferta laboral parecen servir de polo de atracción para instalarse nas ZPP alta próximas, onde se rexistran os saldos migratorios positivos máis elevados que compensan os saldos negativos do resto de zonas rurais. Non obstante, e á falta dunha análise da orixe dos migrantes, cremos que nestas zonas tamén se instala a poboación de orixe estranxeira que buscou traballo — nun inicio — na construción e na industria e, que despois da crise, atopa no sector agro-gandeiro un sector refuxio, tal e como apuntaban Gil-Alonso et al. (2015) para a Cornixa Cantábrica. En Ourense, os saldos positivos das ZPP alta e intermedia tamén compensan o saldo negativo da ZPP baixa, xa de partida deserta en extremo. Apuntamos que podemos estar observando tamén nos tres casos un certo fenómeno de contraurbanización. Tan só en Lugo os sal- 
dos migratorios da ZPP alta non compensan a caída no resto de zonas rurais, ilustrando a inexistencia de núcleos nas cabeceiras de comarca capaces de atraer poboación, así como un fenómeno de despoboamento xeral importante. Así, a concentración e intensificación da actividade gandeira nas zonas da metade setentrional de Galicia non parecen ter servido para atraer poboación á ZPP baixa de xeito que compense os saldos migratorios negativos observados neste traballo. O papel da agricultura intensiva que serviu, no sur de España, para atraer poboación e diversificación económica, non parece observarse en Galicia para as ZPP baixa, en parte porque se trata de procesos produtivos moi distintos: o primeiro intensivo en man de obra (o do sur) e outro intensivo en capital (a gandería). Só a crise e a falta de relevo xeracional das explotacións poden estar facilitando a entrada de migrantes de orixe estranxeira como man de obra asalariada, pero que se instalarían nas cabeceiras de comarca (ZPP alta). Este punto debe ser obxecto de futuras investigacións.

O retroceso poboacional leva parello unha forte redución do capital humano das áreas rurais, onde as persoas máis afectadas son aquelas das que a idade está comprendida entre os 25 e os 34 anos. Trátase da franxa de idade na que se fundan as familias e na que as mulleres se reproducen, polo que o éxodo deste grupo de idade compromete a pervivencia da sociedade rural e incide nunha maior taxa de avellentamento. Deste xeito, a emigración nestes rangos de idade mostra importantes desequilibrios en canto ao sexo, posto que foron as mulleres as que alcanzaron maiores taxas brutas de emigración, de forma similar ao que acontece noutras comunidades autónomas (Camarero e Sampedro, 2008). Esta tendencia relacionouse coa procura de mellores oportunidades laborais, pero tamén mellores servizos e apoio para o coidado da prole. Por debaixo, atópase unha relación entre mercado laboral e lugar de residencia máis ríxida para a muller rural que para o home, máis proclive a non abandonar o lugar de residencia rural grazas a unha maior propensión á mobilidade (commuting) e non á emigración (Camarero e Sampedro, 2008). En consecuencia, o desequilibrio entre poboación nova e anciá increméntase cada vez máis nas zonas rurais, ao igual que a relación de masculinidade, contribuíndo a un maior debilitamento deste territorio. A potenciación deste fenómeno a partires do ano 2008 non foi allea á crise económica, quedando así reflectido na evolución da taxa bruta de emigración entre 2005 e 2015, que ve ralentizar o seu ritmo de incremento.

Aínda que o noso traballo non indaga nas motivacións para migrar, o feito de que os saldos migratorios negativos para o período de estudo se desen fundamentalmente nas zonas rurais máis remotas e que nestas zonas non se freasen co comezo da crise económica, sumado ao feito de que mostren ter un marcado carácter feminino e xove, permítenos aventurar que detrás destes movementos se atopan razóns de tipo laboral, económico e de procura de mellores servizos.

Finalmente, o emprego da clasificación do grao e subgrao de urbanización dos concellos elaborada polo IGE a partir da metodoloxía definida por Eurostat, facilita a elaboración de potenciais estudos migratorios comparados con outros territorios europeos. 


\section{AGRADECEMENTOS}

Este traballo desenvolveuse no marco do convenio entre a USC e o Instituto Galego de Estatística (IGE) para o programa de doutoramento en Xestión Sustentable da Terra e do Territorio. Agradecemos, polo tanto, as achegas do IGE no desenvolvemento desta investigación, especialmente a María Esther Calvo Ocampo e a María Esther López Vizcaíno, así como aos revisores do texto polas súas valiosas achegas. 


\section{BIBLIOGRAFÍA}

Aldrey Vázquez, J. A. (2003): «O estudio da poboación dende a óptica xeográfica: orixe e entidade actual», Revista de Xeografía, Territorio e Medio Ambiente, 3, pp. 31-52.

Aldrey Vázquez, J. A. (2006): A poboación galega, 1900-2005, Vigo, Ir Indo.

Aldrey Vázquez, J. A. e Lois González, R. (2010): Breve Xeografía de Galicia, Vigo, A Nosa Terra.

Aldrey Vázquez, J.A. e Del Río Franqueira, D. (2014): «Crónica de un envejecimiento anunciado: Galicia 2015-2030», in A. López Gay, E. Rojo, M. Solsona, A. Andújar, J. Cruz, R. Iglesias, J.M. Feria e A. Vahi (eds.), XIV Congreso Nacional de Población. Cambio demográfico y socioterritorial en un contexto de crisis, Sevilla, pp. 69-82.

Almås, R., e Haugen, M. S. (1991): «Norwegian gender roles in transition: the masculinization hypothesis in the past and in the future», Journal of Rural Studies, 7, 1-2, pp. 79-83.

Arnalte-Alegre, E. e Ortiz-Miranda, D. (2013): «The Southern Model of European Agriculture Revisited: continuities and dynamics», in D. Ortiz-Miranda, A. MoraguesFaus e E. Arnalte-Alegre (eds.), Agriculture in Mediterranean Europe. Between old and new paradigms, Col. Research in Rural Sociology and Development, vol 19. Emerald, pp. 37-74.

BBSR (2016): Where the population in Europe is growing or shrinking. Visto en https:// www.bbsr.bund.de/BBSR/EN/SpatialDevelopment/SpatialDevelopmentEurope/ AnalysesSpatialDevelopment/Projects/PopulationDevelopment/population-development.html (Visitado 12/06/2018).

Bielza de Ory, V. (2010): «La ordenación de áreas de baja densidad (espacios rurales): comarcalización y planes comarcales», in Bielza de Ory et al., De la ordenación a la planificación territorial estratégica en el ámbito regional-comarcal, Zaragoza, pp. 481-522.

Camarero, L.; Sampedro, R. (2008): «¿Por qué se van las mujeres? El continuum de movilidad como hipótesis explicativa de las masculinización rural», Revista Española de Investigaciones Sociológicas, 124, pp. 73-105.

Cagiao Vila, P. et al. (2013): A emigración galega a América do Sur, A Coruña, Hércules de Ediciones.

Domingo i Valls, A., Coll, A. S. e Rivera, E. O. (2014): «¿Migración neohispánica? El impacto de la crisis económica en la emigración española», Empiria, 29, pp. 39-66.

Eiras Roel, A. (1992): «La emigración gallega a América en los siglos XIX-XX. Nueva panorámica revisada», in Eiras Roel, A. (ed.), Aportaciones al estudio de la emigración gallega, Santiago de Compostela, pp. 185-215.

Ferrás Sexto, C. (2000): «Desde Avión para Jalisco. Historia y perfil socioeconómico de la emigración gallega hacia México en la segunda mitad del siglo XX», Sémata, 11, pp. 381-394. 
Fielding, A. J. (1989): «Migration and Urbanization in Western Europe Since 1950», The Geographical Journal, 155 (1), pp. 60-69.

Gáková, Z. e Dijkstra, L. (2010): «Does population decline lead to economic decline in EU rural regions?», Regional Focus, 01/2010 (Directorate-General for Regional Policy). Visto en: http://ec.europa.eu/regional_policy/sources/docgener/focus/2010_01_population_decline.pdf

García Coll, A. e Sánchez Aguilera, D. (2001): «Las estadísticas demográficas españolas: entre el orden y el caos», Boletín de la A.G.E., 31, pp. 87-109.

García Sanz, B. (2012): «Presente y futuro del mundo rural español», in S.P. Izcara Palacios, K.L. Andrade Rubio e F. Tort Chavarría (coords.), Sociedad Rural y Migración en España, Tamaulipas, pp. 19-51.

Gil-Alonso, F., Carrasco, J. B., e Rúbies, I. P. (2015): «Las migraciones internas de los extranjeros en España: dinámicas espaciales recientes bajo el impacto de la crisis», Boletín de la Asociación de Geógrafos Españoles, 69, pp. 233-261.

Hernández Borge, J. (2003): «Bibliografía geodemográfica de Galicia», in Universidade de Santiago, La dinámica geodemográfica protagonista del territorio. Actas del VIII Congreso de la Población Española, Santiago de Compostela, pp. 103-119.

Hoggart, K. e Paniagua, A. (2001): «What rural restructuring?», Journal of Rural Studies, 17,1, pp. 41-62.

IGE, (2016): «Clasificación das parroquias e dos concellos galegos segundo o grao de urbanización (GU-2016)». Dispoñible en: https://www.ige.eu/estatico/pdfs/s3/clasificacions/urbanizacion/MetodoloxiaGU2016Concellos.pdf

King, R. (2002): «Towards a new map of European migration», International Journal of Population Geography, 8, 2, pp. 89-106.

Lois González, R. e Piñeira Mantiñán, M. (2011): «A rede urbana e a rápida urbanización do territorio», in Piñeira Mantiñán, M. e Santos Solla, X. (coords.), Xeografía de Galicia, Vigo, pp. 158-227.

Lois González, R. e Rodríguez González, R. (2001): «Cambios recentes no espacio rural: a Galicia interior», in San Román Rodríguez, J. M. (dir.), Unha panorámica de Valdeorras. A dinámica dun espacio interior de Galicia. IX Semana de Historia, O Barco de Valdeorras, pp. 29-51.

López de Lera, D., \& Pérez-Caramés, A. (2015): «La decisión de retornar en tiempos de crisis. Una perspectiva comparada de los migrantes ecuatorianos y rumanos en España». Migraciones. Publicación del Instituto Universitario de Estudios sobre Migraciones, 37, pp. 171-194.

Martínez-Filgueira, X., Peón, D. e López-Iglesias, E. (2017): «Intra-rural divides and regional planning: an analysis of a traditional emigration region (Galicia, Spain)», European Planning Studies, 25, 7, pp. 1237-1255.

Marsden, T., Lowe, P. e Whatmore, S. (1990): Rural restructuring: global processes and their responses, London, David Fulton Publishers. 
Mendola, M. (2012): «Rural Out-Migration and Economic Development at Origin: A review of the evidence», Journal of International Development, 24, pp. 102-122.

Núñez Seixas, X. M. (2001): «A emigración. Galicia no mundo», in Freixanes, V. et al., Galicia: unha luz no Atlántico, Vigo, pp. 224-247.

Pazó, J.M. e Moragón, M.P. (2018): «El despoblamiento en Galicia: la visualización de la catástrofe», AGER, 24, pp. 123-154.

Pinilla, Ayuda, e Sáez (2008): «Rural Depopulation and the Migration Turnaround In Mediterranean Western Europe: A Case Study of Aragon», Journal of Rural and Community Development, 3, pp. 1-22.

Poláková, J., Tucker, G., Hart, K., Dwyer, J. e Rayment, M. (2011): «Addressing biodiversity and habitat preservation through measures applied under the Common Agricultural Policy», Institute for European Environmental Policy, London.

Rérat, P. (2014): «The selective migration of young graduates: Which of them return to their rural home region and which do not?», Journal of Rural Studies, 35, pp. 123-132.

Seijas Montero, M. (2011): «Emigrantes lalinenses en América: os exemplos de Bos Aires e A Habana», in Aldrey Vázquez, J. A. e Fernández Ríos, L., Da Galicia de Balbino á Galicia de Hoxe, Pontevedra, pp. 81-109.

Sineiro García, F., López Iglesias, E., Lorenzana Fernández, R. e Valdés Paços, B. (2006): «El proceso de ajuste en la ganadería bovina de la cornisa cantábrica», in Arnalte Alegre, E. (coord.), Políticas agrarias y ajuste estructural en la agricultura española, Madrid, pp. 261-289.

Stockdale, A. (2002): «Out-migration from rural Scotland: The importance of family and social networks», Sociologia Ruralis, 42, 1, pp. 41-64.

Stockdale, A. (2004): «Rural out-migration: community consequences and individual migrant experiences», Sociologia Ruralis, 44, 2, pp. 167-194.

Stockdale, Aileen (2006): «Migration: Pre-requisite for rural economic regeneration?», Journal of Rural Studies, 22, pp. 354-366.

Susino Arbucias, Joaquin (2011): «La evolución de las migraciones interiores en España: una evaluación de las fuentes demográficas disponibles», Papers: revista de sociología, 96, 3, pp. 853-881.

Thissen, F., Fortuijn, J. D., Strijker, D. e Haartsen, T. (2010): «Migration intentions of rural youth in the Westhoek, Flanders, Belgium and the Veenkoloniën, The Netherlands», Journal of Rural Studies, 26, 4, pp. 428-436.

Vázquez, I., Sineiro, F. e Lorenzana R. (2008): «Tipología de municipios rurales de Galicia por indicadores socioeconómicos», in Comunicación XII Congreso Internacional de Ingeniería de Proyectos Zaragoza. Dispoñible en: http://www.usc.es/ecoagra/arquivos//Zaragoza_2008.pdf

Villares Paz, R. (1996): Historia da emigración galega a América, Santiago de Compostela, Xunta de Galicia.

Whatmore, S. (1991): «Life cycle or patriarchy? Gender divisions in family farming», Journal of Rural Studies, 7, 1-2, pp. 71-76. 


\section{ANEXO}

Táboa 1. Principais indicadores demográficos, sociolaborais e económicos segundo o grao e o subgrao de urbanización.

\begin{tabular}{|c|c|c|c|c|c|c|c|}
\hline & ZDP & $\begin{array}{l}\text { ZIP } \\
\text { alta }\end{array}$ & $\begin{array}{c}\text { ZIP } \\
\text { baixa }\end{array}$ & $\begin{array}{l}\text { ZPP } \\
\text { alta }\end{array}$ & $\begin{array}{c}\text { ZPP } \\
\text { intermedia }\end{array}$ & $\begin{array}{c}\mathrm{ZPP} \\
\text { baixa }\end{array}$ & GALICIA \\
\hline Superficie $\left(\mathrm{km}^{2}\right)$ & 982,3 & 2782,2 & 1616,5 & 2281,1 & 2632,3 & 19281 & 29575,4 \\
\hline Poboación (2002) (000 persoas) & 978,9 & 685,6 & 221,5 & 198,8 & 146,5 & 505,6 & $2.737,3$ \\
\hline Poboación (2015) (000 persoas) & 989,9 & 765,8 & 229,7 & 204,1 & 129,3 & 413,3 & 2.732 .3 \\
\hline Idade media (2002) & 41,3 & 40,1 & 41,7 & 44 & 45,5 & 49 & 42,9 \\
\hline Idade media (2015) & 44,9 & 43,6 & 45,1 & 46,9 & 49,6 & 53,2 & 46,2 \\
\hline $\begin{array}{l}\text { Índice sintético de fecundidade } \\
\text { (2002) }\end{array}$ & 0,97 & 1,06 & 0,94 & 0,94 & 0,84 & 0,71 & 0,95 \\
\hline $\begin{array}{l}\text { Índice sintético de fecundidade } \\
\text { (2015) }\end{array}$ & 1,14 & 1,17 & 1,14 & 1,08 & 0,98 & 0,86 & 1,1 \\
\hline Idade media á maternidade (2002) & 31,6 & 30,4 & 30,4 & 30,6 & 30,1 & 30,3 & 30,8 \\
\hline Idade media á maternidade (2015) & 32,9 & 32,4 & 32,0 & 32,3 & 32,4 & 32,1 & 32,5 \\
\hline Índice de masculinidade (2002) & 88,70 & 94,93 & 95,08 & 93,86 & 94,21 & 95,66 & 92,68 \\
\hline Índice de masculinidade (2015) & 87,93 & 95,35 & 95,48 & 95,87 & 95,99 & 98,00 & 93,06 \\
\hline Índice de envellecemento (2002) & 97,7 & 83,9 & 103 & 136,8 & 159,3 & 237,6 & 119,7 \\
\hline Índice de envellecemento (2015) & 129,1 & 107,9 & 130,3 & 165,9 & 232,5 & 365,1 & 151,9 \\
\hline $\begin{array}{l}\% \text { de afiliación á Seguridade } \\
\text { Social no sector da agricultura e } \\
\text { pesca }(2015)\end{array}$ & 1,1 & 5,2 & 8 & 7,4 & 14,7 & 19 & 6,4 \\
\hline $\begin{array}{l}\text { \% de afiliación á Seguridade } \\
\text { Social no sector da construcción } \\
\text { (2015) }\end{array}$ & 5 & 7,7 & 8,8 & 9,9 & 10,3 & 9,9 & 7,4 \\
\hline $\begin{array}{l}\text { \% de afiliacións á Seguridade } \\
\text { Social no sector da industria } \\
(2015)\end{array}$ & 11,1 & 15,6 & 16,2 & 17,1 & 15,2 & 14 & 13,8 \\
\hline $\begin{array}{l}\text { Rendemento medio declarado no } \\
\text { IRPF (2015) (€) }\end{array}$ & $19.588,1$ & $16.083,8$ & $15.011,2$ & $13.915,2$ & $13.915,2$ & 10.514 & $16.328,3$ \\
\hline $\begin{array}{l}\text { Prestacións sociais/Renda } \\
\text { dispoñible bruta (2015) }\end{array}$ & 24,3 & 23,5 & 25,5 & 26,7 & 29,4 & 32,2 & 25,6 \\
\hline
\end{tabular}

Fonte: Panorama rural-urbano (IGE). 